reading of relevant literature and in discussion with a medical librarian.

Results Seven breakthrough pain tools were identified, only one of these - The Breakthrough Pain Questionnaire for Children - was designed for use in children. This tool, however, has not been validated to date. A further 40 studies were identified that used bespoke breakthrough pain assessment tools.

Conclusion There is a lack of validated tools for assessing breakthrough pain, particularly in infants, children and young people. These are urgently needed so that the assessment and management of this distressing symptom can be further improved.

\section{G373(P) WHEN PARENTS AND PROFESSIONALS AGREE: AN EXAMPLE OF SHARED DECISION MAKING IN A CASE OF SPINAL MUSCULAR ATROPHY TYPE 1}

${ }^{1} S$ Shahid, ${ }^{1} \mathrm{~N}$ Punjabi, ${ }^{1} \mathrm{~N}$ Sahdev, ${ }^{1} \mathrm{H}$ Khalid, ${ }^{2} \mathrm{U}$ Khalid, ${ }^{1} \mathrm{~K}$ Punjabi, ${ }^{1} \mathrm{~A}$ Gour. ${ }^{1}$ Paediatric Intensive Care Unit, St George's Hospital, London, UK; ${ }^{2}$ University College London, London, UK

10.1136/archdischild-2020-rcpch.320

Introduction The media has covered many cases on when parents disagree with the opinions of healthcare professionals, most notably in the case of Charlie Gard.

This particular case of a female infant with spinal muscular atrophy (SMA) type 1 is an example of when the decisions of parents align with the advice of healthcare professionals and attempts to uncover what factors may have contributed to this cohesion.

SMA is the term given for a group of genetic disorders leading to muscle atrophy and weakness. Type 1 is the most severe phenotype, presenting under 6 months of age and with a $68 \%$ mortality rate within 2 years of life.

Case Synopsis Female infant $\mathrm{M}$ was born at term, with no concerns, to consanguineous parents. At 7 weeks old, her mother took her to the GP with concerns of a lack of limb movement. Examination found multiple neurological abnormalities, including absent rooting reflex, global hypotonia and upgoing Babinski reflexes. $\mathrm{M}$ was thus diagnosed with SMA Type 1.

At 16 weeks old, $M$ was admitted to the Paediatric Intensive Care Unit with respiratory deterioration requiring intubation. M's parents decided that a tracheostomy would make her quality of life worse, even if it did prove lifeprolonging. They opted to palliate on non-invasive ventilation.

Discussion The decision to palliate a patient is burdensome to all involved and is influenced by many factors.

Evidence shows that parents of those with SMA assess success of care not on outcome, but on factors including positive communication with the healthcare team. Furthermore, those who highly rate their experience of this communication have lower levels of long-term grief.

Ensuring parental understanding at each stage is crucial for shared decision-making. The parents of this patient were involved in every step. Their refusal of a tracheostomy despite the potential for added life is not a common decision and as both parental and professional opinions here aligned, reflects the honest and realistic communication between both parties.
Conclusion This case shows how effective communication between the medical team and parents can improve the parental experience of paediatric palliation and help attain shared decision-making.

\section{G374(P) ABSTRACT WITHDRAWN}

\section{G375(P) ABSTRACT WITHDRAWN}

\section{Trainees}

\section{G376 UK PAEDIATRIC TRAINEE TRANSITION TO REGISTRAR SURVEY}

${ }^{1,2} \mathrm{~A}$ Nye, ${ }^{1,2} \mathrm{HS}$ Hodgson, ${ }^{2} \mathrm{~F}$ Finlay. ${ }^{1}$ Paediatrics, Royal United Hospital, Bath, UK; ${ }^{2}$ Community Child Health, Virgin Care Services Ltd, Bath, UK

10.1136/archdischild-2020-rcpch.321

The transition from paediatric level 1 trainee to registrar can be a turbulent time for trainees given the significant 'step-up' in responsibility, variation in preceding clinical experience, and limited opportunities to develop leadership and management skills during level 1 training.

Aims To explore paediatric trainees' experiences of transitioning to registrar at a national level, to identify challenges and training needs during this period.

Methods All UK paediatric trainees working on the middlegrade rota were invited to complete an online survey designed using Survey Monkey over a four-week period between September and October 2019. Questions specifically focused on; experience and confidence in conducting registrar-level tasks, support available to facilitate transition, and views on how trainees could be better prepared and supported during this period.

Results A total of 79 responses were received from 8 deaneries. 10 incomplete responses were excluded. $43 \%$ of respondents did not feel that overall they were adequately prepared for becoming a registrar. Registrar-level tasks that respondents felt most confident about were: supporting junior colleagues and knowing when to call the consultant. Since becoming a registrar, the most challenging aspects of the role identified were leading resuscitations and managing safeguarding cases. With regards to mandatory Level 1 training procedures, respondents were least confident at intubation, and most confident at cannulation.

Regarding interventions intended to facilitate transition: $23 \%$ had stepped-up in the same department where they had spent the previous 6 months working as an SHO; 42\% had done a step-up simulation course; 39\% had supervised actingup experience; and $17 \%$ had done registrar-level clinics. Respondents felt that the most helpful interventions to aid in transition would be: supervised acting-up experience and more exposure to safeguarding cases during level 1 training.

Conclusion Results from our survey suggest that a significant proportion of paediatric trainees do not feel prepared for stepping-up to the paediatric registrar role. It also highlights poor utilisation of learning experiences aimed at developing 